\title{
EVALUATION OF THE THERMOPLASTICITY OF DIFFERENT GUTTA-PERCHA CONES AND THE TC SYSTEM
}

\author{
Mário TANOMARU-FILHO ${ }^{1}$, Carlos Alexandre Souza BIER ${ }^{2}$, Juliane Maria Guerreiro TANOMARU ${ }^{3}$, Danilo Barbosa BARROS ${ }^{4}$
}

1- DDS, MSc, PhD, Associate Professor, Department of Restorative Dentistry, Araraquara Dental School, São Paulo State University, Araraquara, SP, Brazil.

2- PhD Student in Endodontics, Araraquara Dental School, São Paulo State University, Araraquara, SP, Brazil.

3- DDS, MSc, PhD, Assistant Professor, Department of Restorative Dentistry, Araraquara Dental School, São Paulo State University, Araraquara,

SP, Brazil.

4- DDS, Graduated student, Araraquara Dental School, São Paulo State University, Araraquara, SP, Brazil.

Corresponding address: Prof. Dr. Mário Tanomaru Filho - Rua Humaitá, 1680, Caixa Postal 331, Centro, 14801-903 - Araraquara, SP, Brasil - Phone 5516 33016390, Fax: 5516 3301-6392 - e-mail: tanomaru@uol.com.br

Received: October 06, 2006 - Modification: February 15, 2007 - Accepted: March 13, 2007

\begin{abstract}
$O$

bjective: The aim of this study was to evaluate the thermoplasticity of three commercial brands of gutta-percha (Tanari, Dentsply 0.06, and Roeko), and of the TC system. Materials and Methods: Standardized specimens were fabricated from the materials to be evaluated. Specimens were placed in water at $70^{\circ} \mathrm{C}$ for 60 seconds. Following that, they were positioned between two glass slabs and each set was compressed by a $5 \mathrm{~kg}$ weight. Images of the specimens before and after compression were digitized and analyzed by the Image Tool software. The flow capacity of each material was confirmed by the difference between the initial and final areas of each sample. Results: The resulting data were analyzed by ANOVA. The TC system presented the greatest thermoplasticity values $(\mathrm{p}<0.05)$. Among the gutta-percha cones, the Roeko brand showed higher thermoplasticity than the others $(\mathrm{p}<0.05)$. Conclusion: The gutta-percha from TC system present good thermoplasticity capacity.
\end{abstract}

Uniterms: Endodontics; Root canal obturation; Gutta-percha.

\section{INTRODUCTION}

For endodontic therapy to be successful, it is acknowledged that the root canal should be cleaned, shaped and sealed in its three dimensions ${ }^{19}$.

Several materials and techniques have been used to fill the root canal system. Gutta-percha, used since $1867^{6}$, is the most commonly employed material due to its biocompatibility, dimensional stability, plasticity, and ease of removal when necessary.

Gutta-percha cones consist mainly of gutta-percha and zinc oxide ${ }^{11,16,20}$ in variable ratios, depending on the manufacturing methods. Gurgel-Filho, et al. ${ }^{11}$ (2003) compared five commercial brands of cones and found variations from $14.5 \%$ to $20.4 \%$ for gutta-percha, and from $66.5 \%$ to $84.3 \%$ for zinc oxide. Maniglia-Ferreira, et al. ${ }^{16}(2005)$ studied the chemical composition of some Brazilian guttapercha cones and found a variation from 15.2 to $21.6 \%$ for gutta-percha and from 69.8 to $81.9 \%$ for zinc oxide. These differences may affect the physical and biological properties of gutta-percha cones ${ }^{21}$.

Root canal filling techniques using cold or warm gutta- percha cones have been extensively applied in Endodontics ${ }^{12,14,19,24}$. The lateral condensation method using cold gutta-percha may result in voids between the cones ${ }^{1,12,14}$ and lack of a homogeneous sealing mass ${ }^{4,19}$.

Gutta-percha is a polymer found in two distinct crystalline forms, alpha and beta. Most gutta-percha cones available are in the beta form. The alpha form of gutta-percha is brittle at room temperature, but becomes gluey, adhesive and highly flowable when heated. The beta form, on the other hand, is stable and flexible at room temperature. When heated, it is less adhesive and flowable than the alpha form ${ }^{9}$.

Since 1967, when Shilder ${ }^{19}$ introduced the vertical condensation technique using warm gutta-percha, a large number of thermoplastic methods have been proposed. Some of these methods, such as Thermafil $1^{1,5,12}$, Ultrafil ${ }^{5}$ and Microseal $^{2,3,15}$ use gutta-percha in the alpha form.

The clinical advantages of the alpha form of gutta-percha resulted in the development of the Microseal system (Sybron Endo, Orange, CA, USA). A similar process of thermoplastic obturation, the TC system (Tanaka de Castro \& Minatel Ltda., Cascavel, PR, Brazil), was developed and patented in 2002, aiming at making this technique more accessible while 
preserving its main properties.

Few studies have evaluated the thermoplasticity of different brands of gutta-percha ${ }^{10,21}$ and its different forms, alpha and beta.

The aim of this study was to compare the flow capacity of three distinct brands of gutta-percha cones (Tanari, Dentsply 0.06 and Roeko) to that of gutta-percha cones in the TC system.

\section{MATERIAL AND METHODS}

For thermoplasticity analyses, five specimens, measuring $10 \mathrm{~mm}$ in diameter and $1.5 \mathrm{~mm}$ in thickness were fabricated from each brand of gutta-percha, as shown in Table 1.

Material samples were kept in water at $70^{\circ} \mathrm{C}$ for 60 seconds, using a thermometer-controlled heating apparatus (Righetto e Cia., Campinas, SP, Brazil).

The heated materials were then placed into standardized rings in the dimensions above described, and pressed between two glass slabs under controlled and constant pressure of $0.5 \mathrm{~N}$ for one minute. Thereafter, the specimens were removed from the molds, the excess material was trimmed and dimensions were checked. Specimens were kept at a temperature between $25-30^{\circ} \mathrm{C}$ for $24 \mathrm{~h}$ and then returned to the heating apparatus at $70^{\circ} \mathrm{C}$ for 60 seconds. Following that, the specimens were once again positioned between two glass slabs and a $5 \mathrm{~kg}$ weight was placed on top of the slabs to create compression for three minutes, until the material cooled. The image of each specimen was digitized before and after compression and analyzed by the Image Tool software (UTHSCSA Image Tool for Windows version 3.0, San Antonio, TX, USA) to determine its area in $\mathrm{mm}^{2}$. The thermoplasticity of the materials was determined by the difference between the initial and final areas of each specimen.

The resulting data were analyzed by ANOVA with a significance level of $0.05 \%$.

\section{RESULTS}

Means and standard deviation for the differences between initial and final areas of each material are shown in Figure 1. Results showed that the TC system presented the highest thermoplasticity values $(p<0.05)$. Among the guttapercha cones, the Roeko brand presented greater plasticity than the other tested brands $(\mathrm{p}<0.05)$.

\section{DISCUSSION}

The goal of root canal filling techniques using warm gutta-percha is to achieve a homogenous obturating mass and to successfully fill irregularities in the root canals ${ }^{1,4,7-}$ $10,12,14,19,21,22,24$, while promoting a better apical seal ${ }^{2}$. These methods rely on the thermoplasticity of the cones, which may vary among the different commercial brands of guttapercha $^{10,21}$.

Studies to evaluate the plastification ability of guttapercha have been performed in flat root canals ${ }^{24}$, natural teeth with artificially produced irregularities ${ }^{1,4,7,8}$, accessory canals in demineralized teeth ${ }^{22}$, artificial teeth with simulated canals $^{10}$, and metal blocks with accessory canals ${ }^{21}$. In order to standardize the variables and to better assess the thermoplasticity of the tested materials, the ADA specification No. 57 (ISO 6876 standard - Dental Root Canal Sealing Materials), which refers to the measurement of the flow capacity of sealing materials, was adapted in the present study to gutta-percha testing. To evaluate the flowing ability of endodontic sealers, a $120 \mathrm{~g}$ weight is applied. The findings of preliminary studies showed that the force required to provide a significant increase in the diameter of heated guttapercha specimens should be greater that $3 \mathrm{~kg}$. In the present study, a 5-kg weight was used.

According to Shilder, et al. ${ }^{20}$ (1974), gutta-percha has two endothermic peaks. The first peak occurs between 42 and $49^{\circ} \mathrm{C}$ and corresponds to the transformation from the

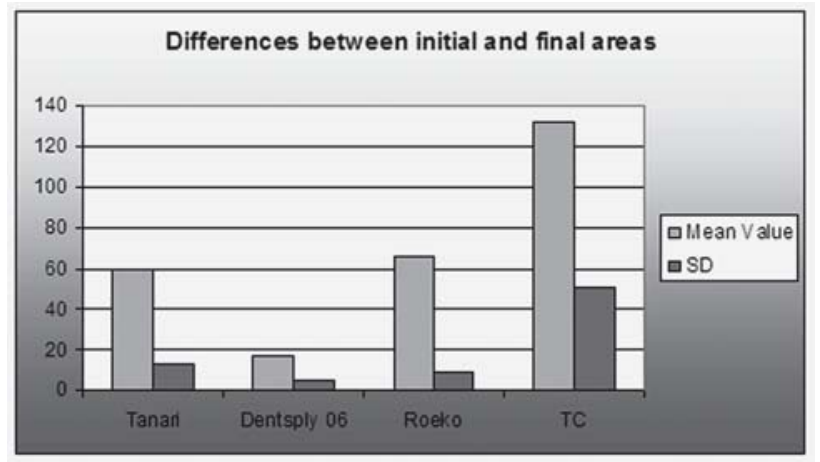

FIGURE 1- Means and standard deviations for the differences between initial and final areas of the experimental groups

TABLE 1- Endodontic filling materials used in the experimental groups

MATERIAL

Tanari

Dentsply 0.06

Roeko

TC System
MANUFACTURER

Tanariman, Manacapuru, AM, Brazil

Dentsply Indústria e Comércio Ltda., Petrópolis, RJ, Brazil

Roeko, Langenau, Germany

Tanaka de Castro \& Minatel Ltda, Cascavel, PR, Brazil 
beta phase to the alpha phase, while the other peak occurs between 53 and $59^{\circ} \mathrm{C}$, when the material changes from the alpha phase to the amorphous phase. Miner, et al. ${ }^{18}$ (2006) reported that the melting point of gutta-percha is at $60^{\circ} \mathrm{C}$. Combe, et al. ${ }^{17}$ (1992) compared the endothermic peaks of non-industrialized gutta-percha to 15 commercial brands of gutta-percha using the temperature of $70^{\circ} \mathrm{C}$. Based on the findings of these investigations, a temperature of $70^{\circ} \mathrm{C}$ was chosen for the present study.

It is difficult to establish the amount of temperature rise on the dentin surrounding the heated gutta-percha during root canal obturation. Venturi, et al. ${ }^{23}$ (2002) evaluated the temperature change of gutta-percha and root dentin after vertical condensation technique using the System-B Heat Source and observed minimal temperature increase on the external root surface, which suggests lack of damage to the periradicular tissues.

Our results showed differences among the tested products. The TC system presented higher thermoplasticity. Among the gutta-percha cones, the Roeko cones had better results compared to the other tested brand. The results presented by the TC system are related to the thermal treatment of the material during the manufacturing process, resulting in alpha gutta-percha, with higher thermoplasticity ${ }^{9}$, as demonstrated in this study. Gutta-percha is a natural polymer that undergoes industrial processing and addition of other substances before its application in Dentistry. This may affect the thermoplasticity behavior of this material. Kolokuris, et al. ${ }^{13}$ (1992) verified that the thermoplastic properties of gutta-percha depend directly on its composition, being more pronounced in its pure form than in the industrialized version.

The different results obtained with the tested guttapercha brands may be related to the amount of organic and inorganic components in the product. Other studies advise that the amount of inorganic fillers added to the material during fabrication of the cones may affect its properties $^{13,17,20,21}$.

Gurgel-Filho, et al. ${ }^{11}$ (2003) performed chemical and radiographic studies with five commercial brands of guttapercha and found that the variation in the amounts of zinc oxide and gutta-percha affected the flow capacity of the products ${ }^{10}$. Commercial brands with higher amounts of guttapercha ${ }^{11}$ in their composition demonstrated better ability to fill simulated accessory canals ${ }^{10}$. Nevertheless, due to the peculiar anatomical characteristics of the root canal system, further studies are required to investigate the capacity of different types of gutta-percha in adequately filling lateral canals.

Brosco, et al. ${ }^{2}$ (2003) evaluated several obturation techniques and verified that the Microseal system presented the least apical leakage. The authors attributed these results to the physical properties inherent to the alpha form of guttapercha: high adhesion ability, low melting point and ability to adapt to the apical portion of the root canals.

When thermomechanical root canal filling techniques are used, the attrition between the compactor and the guttapercha cones generates heat. This heat plasticizes the gutta- percha, which is then laterally and apically condensed against the canal walls. Our results showed that gutta-percha behaves differently when heated, which may affect its application in thermoplastic obturation techniques.

The present study may be considered as an initial model for thermoplasticity evaluation. Further research is required to increase the accuracy and standardization of the analysis of the thermoplastic properties of gutta-percha and similar root canal filling materials.

\section{CONCLUSIONS}

Based on the results of the present study, it may be concluded that different commercial brands of gutta-percha presented different thermoplasticity values. In addition, it was observed that the gutta-percha in the TC obturation system had the highest thermoplastic ability, which is consistent with gutta-percha in the alpha form.

\section{REFERENCES}

1- Bowman C, Baumgartner JC. Gutta-percha obturation of lateral grooves and depressions. J Endod. 2002;28:220-3.

2- Brosco HV, Bernardineli N, Moraes IG. In Vitro evaluation of the apical sealing of root canals obturated with different techniques. J Appl Oral Sci. 2003;11:181-5

3- Cathro PR, Love RM. Comparison of Microseal and System B/ Obtura II obturation techniques. Int Endod J. 2003;36:876-82.

4- Clinton K, Himel VT. Comparison of a warm gutta-percha obturation technique and lateral condensation. J Endod. 2001;27:6925 .

5- Combe EC, Cohen BD, Cummings K. Alpha and beta forms of gutta-percha in products for root canal filling. Int Endod J. 2001;34:447-51

6- Cruse WP, Bellizzi R. A historic review of endodontics: 16891963. Part 1. J Endod. 1980;6:495-9.

7- Goldberg F, Artaza LP, De Silvio A. Effectiveness of different obturation techniques in filling of simulated lateral canals. J Endod. 2001;27:362-4.

8- Goldberg F, Massone EJ, Esmoris M, Alfie D. Comparison of different techniques for obturating experimental internal resorptive cavities. Endod Dent Traumatol. 2000;16:116-21.

9- Goodman A, Schilder H, Aldrich W. The thermomechanical properties of gutta-percha II: the history and molecular chemistry of gutta-percha. Oral Surg Oral Med Oral Pathol. 1974;37:954-61.

10- Gurgel-Filho ED, Feitosa JPA, Gomes BPFA, Ferraz CCR, SouzaFilho FJ, Teixeira FB. Assessment of different gutta-percha brands during the filling of simulated lateral canals. Int Endod J. 2006;39:1138 .

11- Gurgel-Filho ED; Feitosa JPA, Teixeira FB, Monteiro de Paula RC, Araújo Silva JB, Souza-Filho FJ. Chemical and x-ray analyses of five brands of dental gutta-percha cone. Int Endod J. 2003;36:302-7. 
12- Jarrett IS, Marx D, Covey D, Karmazin M, Lavin M, Gound T. Percentage of canals filled in apical cross sections: an in vitro study of seven obturation techniques. Int Endod J. 2004;37:392-8.

13- Kolokuris I, Arvanitoyannis I, Blanshard JMV, Robinson C. Thermal analysis of commercial gutta-percha using differential scanning colorimeter and dynamic mechanical thermal analysis. J Endod. 1992;18:4-9.

14- Lea CS, Apicella MJ, Mines P, Yancich PP, Parker MH. Comparison of the obturation density of cold lateral compaction versus warm vertical compaction using the continuous wave of condensation technique. J Endod. 2005;31:37-9.

15- Maggiore F. Microseal systems and modified technique. Dent Clin North Am. 2004;48:217-64.

16- Maniglia-Ferreira C, Silva JBA Jr, Paula RCM, Feitosa JPA, Cortez DGN, Zaia AA, et al. Brazilian gutta-percha points. Part I: chemical composition and X-ray diffraction analysis. Braz Oral Res. 2005;19:193-7.

17- Marciano J, Michailesco P, Charpentier E, Carrera LC, Abadie MJM. Thermomechanical analysis of dental gutta-percha. J Endod. 1992;18:263-70.

18- Miner MR, Berzins DW, Bahcall JK. A comparison of thermal properties between gutta-percha and a synthetic polymer based root canal filling material (Resilon). J Endod. 2006;32:683-6.

19- Schilder H. Filling root canals in three dimensions. Dent Clin North Am. 1967;11:723-44.

20- Schilder H, Goodman A, Aldrich W. The thermomechanica properties of gutta-percha. Part III: determination of phase transition temperatures for gutta-percha. Oral Surg Oral Med Oral Pathol. 1974;38:109-14

21- Tagger M, Gold A. Flow of various brands of gutta-percha cones under in vitro thermomechanical compaction. J Endod. 1988;14:11520

22- Venturi M, Di Lenarda R, Prati C, Breshi L. An in vitro model to investigate filling of lateral canals. J Endod. 2005;31:877-81.

23- Venturi M, Pasquantonio G, Falconi M, Breschi L. Temperature change within gutta-percha induced by the System-B Heat Source. Int Endod J. 2002;35:740-6.

24- Wu MK, Kastáková A, Wesselink PR. Quality of cold and warm gutta-percha fillings in mandibular premolars. Int Endod J. 2001;34:485-91. 